\title{
Determinantes dos padrões de carreira política dos deputados federais paulistas entre as legislaturas 49a (1991-1995) e 53a (2007-2011)
}

\author{
\begin{tabular}{c}
\hline \hline Wagner Pralon Mancuso \\
Escola de Artes, Ciências e Humanidades \\
Universidade de São Paulo \\
Carolina Uehara \\
Graduada em Gestão de Políticas Públicas \\
Escola de Artes, Ciências e Humanidades \\
Universidade de São Paulo \\
Anita de Cássia Sbegue \\
Graduada em Gestão de Políticas Públicas \\
Escola de Artes, Ciências e Humanidades \\
Universidade de São Paulo \\
Caroline Miranda Sampaio \\
Graduada em Gestão de Políticas Públicas \\
Escola de Artes, Ciências e Humanidades \\
Universidade de São Paulo \\
\hline \hline
\end{tabular}
}

Resumo: 0 objetivo deste artigo é analisar os fatores determinantes dos padrões de carreira política adotados pelos deputados federais paulistas no período das legislaturas $49^{\mathrm{a}}$ (1991-1995) à 53 ${ }^{\mathrm{a}}$ (2007-2011). Com uso de técnicas estatísticas tais como teste qui-quadrado, teste exato de Fisher e regressão logística, o artigo conclui que: i) a opção de saída da vida política está associada aos níveis de concentração eleitoral e competitividade local bem como ao perfil de atuação parlamentar; ii) o êxito em campanhas de reeleição está associado ao acúmulo de capital político, ao perfil de atuação parlamentar e à fidelidade partidária; e iii) o êxito na disputa pela chefia de executivos municipais está associado ao nível de competitividade eleitoral local.

Palavras-chave: carreira política; deputado federal; Câmara dos Deputados; reeleição; estratégia política

Abstract: This article aims to analyze the determinants of political career patterns among federal deputies elected by the State of São Paulo (Brazil) for the $49^{\text {th }}\left(1991\right.$-1995) $\cdot 53^{\text {rd }}(2007-2011)$ legislatures. By using statistical techniques such as chi-squared test, Fisher's exact test and logistic regression, this article concludes that: i) exit of political life is associated with the levels of electoral concentration and local competitiveness, as well as with the parliamentary behavior; ii) success in re-election campaigns is associated with the accumulation of political capital, with the parliamentary behavior and with partisan loyalty; and iii) success in mayoral campaigns is associated with the level of local electoral competitiveness.

Keywords: political career; federal deputy; Chamber of Deputies; reelection; political strategy 
MANCUSO, W. P. et al. Determinantes dos padrões de carreira política dos deputados...

\section{Introdução e balanço da literatura}

Este artigo focaliza os padrões de carreira política dos deputados federais eleitos pelo estado de São Paulo entre 1990 (para a 49a legislatura, de 1991 a 1995) e 2006 (para a 53 legislatura, de 2007 a 2011) e seu objetivo é analisar os fatores determinantes dos padrões de carreira adotados pelos deputados federais paulistas no período considerado.

Ainda há poucos estudos sobre os fatores que determinam os padrões de carreira dos deputados federais brasileiros. Leoni, Pereira e Rennó (2003) e Pereira e Rennó (2003) são os pioneiros nesse campo ${ }^{1}$. Leoni, Pereira e Rennó (2003) investigam os determinantes da escolha de carreira dos deputados federais brasileiros da 50 legislatura (1995-1999). Em artigo de tema similar, Pereira e Rennó (2003) analisam os fatores que afetaram as chances de reeleição dos deputados federais nas eleições de 1998. Em trabalho posterior, Pereira e Rennó (2007) voltam a focalizar os deputados bem sucedidos na disputa pela reeleição, tratando agora de duas legislaturas: a 50 e a $51^{\text {a }}$ (1995-2003). No mesmo ano, Botero e Rennó (2007) fazem uma análise comparativa dos sistemas eleitorais brasileiro e colombiano, bem como dos incentivos que esses sistemas oferecem aos parlamentares em termos de estratégias eleitorais. Na sequência, sintetizamos as principais conclusões desses estudos.

O trabalho de Leoni, Pereira e Rennó (2003) testa uma ideia do cientista político norteamericano David Samuels que, analisando o caso brasileiro, afirma que "os deputados (...) mais vulneráveis eleitoralmente e menos competentes no desempenho das funções de representantes concorrem à reeleição, enquanto os mais capazes concorrem a postos mais altos" (SAMUELS apud LEONI, Pereira e RenNó, 2003, p. 46). Samuels associa, portanto, o bom desempenho das funções parlamentares a voos políticos "mais altos", e um desempenho parlamentar medíocre à opção pela reeleição. Inspirados pela afirmação de Samuels, os autores investigam empiricamente a influência do desempenho parlamentar sobre as opções de carreira dos deputados federais brasileiros. Os autores tomam a ocupação de posições institucionais de poder (por exemplo: cargos da Mesa Diretora da Câmara e liderança de comissões) como indicador de bom desempenho parlamentar. As opções de carreira por eles focalizadas são as seguintes: saída (não se candidatar a nenhum cargo), estática (concorrer à reeleição) e progressiva (concorrer ao senado ou a cargos do Poder Executivo, como prefeito e governador) ${ }^{2}$. Para controlar o efeito da variável de desempenho parlamentar sobre as opções de carreira, consideram também o impacto de outras variáveis, tais como idade, ideologia, antiguidade na Câmara, pertencimento à base presidencial, perfil eleitoral e capacidade de entrega de benefícios clientelistas às bases eleitorais ("pork barrel"). Com base na análise dos dados da eleição de 1998, os autores constatam - diferentemente de Samuels - que a ocupação de posições institucionais de poder favorece o êxito tanto na ambição estática quanto na ambição progressiva ${ }^{3}$. Constatam também que a opção de saída da vida política está ligada à menor capacidade de entrega de "pork" às bases eleitorais, bem como ao menor sucesso eleitoral em disputas anteriores.

\footnotetext{
${ }^{1}$ Na literatura internacional, Schlesinger (1966), Black (1972), Rohde (2012) [1979], Brace (1984) e Kiewiet e Zeng (1993) são obras de referência para o estudo de carreiras políticas. Os trabalhos discutidos nesta seção dialogam com essas obras.

${ }^{2}$ A opção regressiva (concorrer a um cargo legislativo estadual ou municipal) também é mencionada no artigo, mas não é analisada em detalhe.

30 pertencimento a comissões especiais estaria particularmente ligado ao êxito na opção progressiva e a presidência de comissões permanentes ao sucesso na opção estática (LEONI; PeREIRA e RenNó, 2003, p. 62).
} 
Após o esforço inicial para descobrir os determinantes das múltiplas opções de carreira disponíveis para os deputados federais, Pereira e Rennó (2003) concentram a atenção no estudo da opção estática, propondo descobrir os fatores que aumentam as chances de reeleição para a Câmara dos Deputados. Nesse estudo, os autores novamente focalizam apenas os dados da eleição de 1998. A conclusão principal é que o sucesso da opção estática está ligado, sobretudo, à capacidade de entrega de benefícios clientelistas às bases eleitorais. Em outras palavras, os mandatários que querem ser reeleitos precisam trazer 'pork' para seus distritos. Adicionalmente, os autores constatam que a migração para partidos de oposição, durante o mandato, prejudica significativamente a chance de reeleição.

Em artigo posterior, Pereira e Rennó (2007) voltam a focalizar os determinantes da reeleição, olhando agora não apenas para as eleições de 1998, mas também para as de 2002. Os resultados da análise mostram que, nas duas eleições, o sucesso da opção estática esteve ligado aos seguintes fatores: maior execução das emendas parlamentares individuais; pertencimento a um partido da base presidencial no Congresso; menor número de migrações partidárias; melhor desempenho eleitoral em eleições anteriores e menor concentração geográfica dos votos. Especificamente nas eleições de 1998, outros fatores que favoreceram o êxito reeleitoral foram a ocupação de cargos na Mesa Diretora da Câmara e maior investimento financeiro na campanha eleitoral. Já nas eleições de 2002, outros fatores relevantes para a reeleição foram o valor das emendas executadas na principal base eleitoral do candidato na eleição anterior; grau de apoio elevado às proposições de interesse da Presidência da República; ocupação de relatorias em comissões temáticas; menor magnitude do distrito eleitoral (mais assentos em disputa aumentam a competição e reduzem a chance de reeleição) e condição empresarial do candidato. Portanto, Pereira e Rennó (2007) verificam, mais uma vez, que o atendimento de demandas locais aumenta as chances de sucesso reeleitoral. Tal capacidade de atendimento, por sua vez, seria favorecida pela boa relação do deputado com a Presidência da República. Esta conclusão é reforçada pelo trabalho de Figueiredo e Limongi (2008), segundo o qual "o governo favorece os parlamentares de sua base em quase todas as unidades orçamentárias" (FIGUEIREDO e LIMONGI, 2008, p.103), no que tange à execução de emendas individuais referentes a gastos com investimentos.

Noutro trabalho, ao fazer uma análise comparativa dos sistemas eleitorais brasileiro e colombiano, Botero e Rennó (2007) também apontam, nos dois casos, o pertencimento à base como fator importante no que se refere ao êxito de tentativas de reeleição.

O objetivo deste artigo é colaborar para o estudo dos determinantes das opções de carreira dos deputados federais. Há semelhanças e diferenças em relação aos esforços pioneiros reconstituídos até aqui. Quanto às primeiras, este artigo também analisa o efeito de diferentes variáveis sobre os padrões de carreira adotados pelos deputados federais. Assim, a variável dependente aqui utilizada são as opções de carreira dos deputados federais paulistas. Entendemos que os deputados federais, uma vez eleitos, deparam-se com quatro opções de carreira: a opção de saída (não concorrer a nenhum cargo), a opção subnacional (concorrer a cargos legislativos municipais ou estaduais), a opção estática (tentar a reeleição como parlamentar federal, seja para a própria Câmara ou para o Senado) e a opção executiva (candidatar-se à chefia dos executivos municipal, estadual ou federal; ou então assumir cargos na 
MANCUSO, W. P. et al. Determinantes dos padrões de carreira política dos deputados...

estrutura dos diversos níveis de governo, tais como ministérios, secretarias e presidência de estatais, dentre outros) $)^{4}$.

Por sua vez, as variáveis independentes analisadas neste artigo são as seguintes: perfil eleitoral do deputado; pertencimento do deputado à base de apoio presidencial no Congresso; pertencimento do deputado à coligação eleitoral vitoriosa na disputa à Presidência; perfil de atuação parlamentar; e perfil de atuação partidária. Como será mostrado, diversos indicadores foram utilizados para mensurar cada uma das variáveis independentes ${ }^{5}$. A ideia é medir o impacto efetivo dessas potenciais variáveis explicativas sobre a variável dependente.

Quanto às diferenças, em primeiro lugar, o artigo focaliza simultaneamente diversas opções de carreira, ao passo que a maior parte dos estudos analisados focaliza, exclusivamente, a opção estática ${ }^{6}$. Em segundo lugar, este artigo abrange mais legislaturas, cobrindo todo o período que vai da legislatura $49^{a}$ à $53^{a}$. Por outro lado, embora o estudo cubra mais legislaturas e diversas opções de carreira, focaliza apenas os deputados federais eleitos pelo estado de São Paulo. Estudos de abrangência nacional, como os citados neste balanço da literatura, são muito importantes por mostrarem as tendências gerais que operam no conjunto do país. Todavia, estudos de estados específicos também se justificam, porque permitem verificar se as tendências gerais operam neles de forma homogênea, ou se há variações impostas pelos contextos locais. Testar hipóteses de abrangência nacional em subunidades geográficas de uma mesma nação é estratégia explicitamente recomendada, por exemplo, por King, Keohane e Verba (1994, p. 219-220). Esta estratégia é particularmente promissora no caso em tela, pois, nas eleições brasileiras para a Câmara dos Deputados, os distritos eleitorais são os vinte e seis estados e o Distrito Federal. São Paulo foi o estado escolhido como foco deste estudo por ser o distrito eleitoral de maior magnitude, elegendo 70 deputados federais, o que corresponde a 13,7\% dos assentos da Câmara. Sendo assim, o foco nesse estado, em cinco legislaturas consecutivas, permite que se controle o fator "variação de contexto local" e, ao mesmo tempo, garante um número de observações adequado ao tratamento estatístico dos dados ${ }^{7}$.

\footnotetext{
${ }^{4}$ Nossa tipologia de opções de carreira é ligeiramente diferente da tipologia adotada por Leoni, Pereira e Rennó (2003). Em primeiro lugar, o que os autores chamam de opção regressiva nós chamamos de opção subnacional. Em segundo lugar, consideramos que a disputa por uma cadeira do Senado configura opção estática, em vez de opção progressiva, pois o candidato, quando bem sucedido, continua no Legislativo Federal, recebendo remuneração idêntica (embora com mandato mais extenso). Além disso, a Constituição brasileira não estabelece hierarquia entre as Casas do Congresso Nacional, atribuindo poderes legislativos muito semelhantes aos membros das duas Casas. Em terceiro lugar, nomeamos a busca por cargos no Executivo de opção executiva, em vez de opção progressiva, pois a Constituição brasileira não estabelece hierarquia entre os poderes do Estado.

${ }^{5}$ Portanto, este artigo é diretamente inspirado nos trabalhos apresentados, mas não cobre exatamente as mesmas variáveis e os mesmos indicadores por eles utilizados.

${ }^{6}$ A literatura nacional também possui trabalhos dedicados ao estudo de outras opções de carreiras, tais como a opção executiva (BOURDOUKAN, 2005) e a opção de saída (FLORENTINO, 2008). Os achados do presente artigo serão cotejados com a literatura nacional pertinente.

7 Nas Considerações Finais, apontamos a comparação entre estados, em diversas legislaturas, como sugestão para estudos futuros. Tais estudos comparativos e longitudinais permitiriam investigar se há diferenças significativas entre os estados e os porquês dessas eventuais variações.
} 
OPINIÃO PÚBLICA, Campinas, vol. 19, n², novembro, 2013, p. 430-448

\section{Análise dos Dados}

Tabela 1

Opção de carreira dos deputados federais paulistas (1991-2011)

\begin{tabular}{|l|c|c|}
\hline & $\mathbf{N}$ & $\mathbf{\%}$ \\
\hline Saída & $\mathbf{5 1}$ & $\mathbf{1 2 , 7}$ \\
\hline Estática & $\mathbf{3 1 1}$ & $\mathbf{7 7 , 3}$ \\
\hline Câmara, bem sucedida & 189 & 60,8 \\
\hline Câmara, mal sucedida & 117 & 37,6 \\
\hline Senado, bem sucedida & 2 & 0,6 \\
\hline Senado, mal sucedida & 3 & 1,0 \\
\hline Executiva & $\mathbf{2 7}$ & $\mathbf{6 , 7}$ \\
\hline Executiva, bem sucedida & 22 & 81,5 \\
\hline Executiva, mal sucedida & 5 & 18,5 \\
\hline Subnacional & $\mathbf{1 3}$ & $\mathbf{3 , 2}$ \\
\hline Subnacional, bem sucedida & 6 & 46,1 \\
\hline Subnacional, mal sucedida & 7 & 53,9 \\
\hline Total & $\mathbf{4 0 2}$ & $\mathbf{1 0 0 , 0}$ \\
\hline
\end{tabular}

Fonte: Banco de dados sobre carreiras políticas dos deputados federais paulistas (1991-2011).

A Tabela 1 mostra que, ao longo do período estudado, a opção de carreira preferida pela grande maioria dos deputados federais paulistas foi a opção estática (311 casos em 402, ou seja, $77,3 \%)^{8}$. Dentre esses deputados, praticamente todos pleitearam a permanência nos quadros da Câmara e, na maioria dos casos (60,8\%), esta ambição foi bem sucedida ${ }^{9}$. A segunda opção de carreira mais comum foi a opção de saída, adotada 51 vezes (12,7\% dos casos). A terceira opção mais frequente foi a opção executiva, tentada em 27 oportunidades (6,7\% dos casos) e bem sucedida na maioria das vezes $(81,5 \%)^{10}$. Pouquíssimos deputados fizeram a opção de carreira subnacional, o que ocorreu apenas 13 vezes (ou seja, em 3,2\% dos casos) ${ }^{11}$.

A partir daqui pretendemos identificar os fatores determinantes dessas opções de carreira. A estratégia de análise adotada é a seguinte: em primeiro lugar, construímos tabelas de contingência em

\footnotetext{
${ }^{8} \mathrm{O}$ banco de dados que deu origem a este artigo pode ser solicitado aos autores. Cada um dos 402 casos corresponde a um deputado federal, numa das cinco legislaturas analisadas. Analisamos as opções de carreiras tanto dos deputados titulares quanto dos deputados suplentes que tenham, em qualquer momento da legislatura e por qualquer período, ocupado alguma cadeira da Câmara. Um mesmo deputado corresponde a tantos casos quantas tenham sido as legislaturas em que ocupou, como titular ou suplente, alguma cadeira da Câmara.

9 Neste artigo, quando se analisa a opção estática, levam-se em conta, exclusivamente, as recandidaturas à Câmara dos Deputados. A disputa por cadeiras do Senado ocorre sob regras muito diferentes e é rara entre os deputados federais paulistas, o que dificulta a análise estatística. No mesmo período (FLORENTINO, 2008, p. 53), o percentual nacional de recandidaturas de deputados federais foi ligeiramente superior ao observado em São Paulo ( $81 \%$ contra $76,1 \%$ ), e o percentual nacional de reeleição de deputados federais foi bem próximo ao do estado $(60,8 \%$ contra $61,8 \%)$.

10 Consideram-se aqui apenas as candidaturas a cargos executivos eletivos, para evitar dupla contagem. Em 38 casos, deputados federais paulistas ocuparam, durante o mandato, cargos de livre nomeação no Poder Executivo, em níveis federal, estadual ou municipal. Após essa passagem pelo Executivo, em 28 casos, os nomeados acabaram disputando a reeleição para o Legislativo Federal (isto é, em $73,7 \%$ das vezes) e, nos 10 casos restantes, optaram pela saída.

11 Por causa do pequeno número de casos disponíveis para análise, não foi possível focalizar os determinantes da opção subnacional. Concordamos, no entanto, com o comentário do parecerista anônimo, que compreendeu nossa opção metodológica, mas destacou a importância do estudo dos casos "menos prováveis".
} 
MANCUSO, W. P. et al. Determinantes dos padrões de carreira política dos deputados...

que os indicadores das variáveis independentes são cruzados com as opções de carreira focalizadas no artigo. Após a construção das tabelas de contingência, apresentamos modelos de regressão logística, inicialmente, univariados, para cada uma das variáveis independentes identificadas como estatisticamente significativas (ou próximas deste valor) por meio das tabelas de contingência. Na sequência, realizamos testes para encontrar o modelo de regressão logística mais ajustado para cada uma das opções de carreira ${ }^{12}$. A última seção contém as Considerações Finais.

Tabelas de contingência

A primeira variável independente cujos efeitos são analisados é o perfil eleitoral dos deputados. Os indicadores dessa variável são os seguintes: i) grupos de votação; ii) grupos de concentração eleitoral e iii) grupos de competitividade local. O indicador "grupos de votação" foi construído da seguinte maneira: o número de votos recebidos pelo candidato na eleição anterior para deputado federal foi dividido pelo número de votos válidos naquela eleição, no estado, para o mesmo cargo. O resultado desse cálculo indicou o percentual de votos obtidos pelos candidatos. A partir desse cálculo, os deputados foram divididos em três grupos de tamanho aproximadamente igual: o grupo dos deputados mais votados, o grupo dos deputados de votação intermediária e o grupo dos deputados menos votados. Já o indicador "grupos de concentração eleitoral" foi construído da seguinte maneira: o total de votos obtidos pelo candidato no município em que obteve mais votos na eleição anterior foi dividido pelo total de votos obtidos pelo candidato naquela eleição em todo o estado. A partir desse cálculo, os deputados foram novamente divididos em três grupos de tamanho aproximadamente igual: o grupo dos deputados de votação geograficamente mais concentrada, o grupo dos deputados de concentração eleitoral intermediária e o grupo dos deputados de concentração eleitoral mais baixa. Por sua vez, o indicador "grupos de competitividade local" foi construído assim: do total de votos obtidos pelo candidato no município em que ele obteve mais votos na eleição anterior foi subtraído o total de votos obtido pelo candidato (diferente do primeiro) com maior votação neste município. Nesse caso, uma diferença positiva indica que o candidato em questão foi o mais votado naquele município - sendo, portanto, localmente competitivo. Uma diferença negativa indica que outro candidato foi mais votado naquele município: quanto maior a diferença negativa, menor a competitividade local do candidato. Mais uma vez, os deputados foram divididos em três grupos de tamanho aproximadamente igual: o grupo dos candidatos de maior competitividade local, o grupo de candidatos de competitividade local intermediária e o grupo dos candidatos localmente menos competitivos.

A hipótese geral, nesse caso, é que o perfil eleitoral dos deputados influencia a escolha pelas opções de carreira. De forma mais detalhada, as hipóteses testadas são as seguintes: i) menores índices de votação, concentração eleitoral e competitividade local, na eleição anterior, favorecem a opção de saída e ii) maiores índices de votação, concentração eleitoral e competitividade local, na eleição anterior, favorecem o êxito nas opções estática e executiva ${ }^{13}$. 0 índice de votação indica consolidação da carreira política: supõe-se que os deputados com menor índice de votação tendem mais a optar pela saída, e que deputados com maior índice de votação e, portanto, com carreiras mais consolidadas, tendem mais a

12 Todos os testes estatísticos apresentados no artigo foram realizados com o programa SPSS 19.

13 Como havia relativamente poucos casos de deputados que escolheram a opção executiva, esses deputados foram divididos em apenas dois grupos. 
OPINIÃO PÚBLICA, Campinas, vol. 19, n², novembro, 2013, p. 430-448

permanecer na vida política, buscando a reeleição ou cargos executivos. Os indicadores de concentração eleitoral e competitividade local, por sua vez, mostram se o parlamentar possui uma base eleitoral geograficamente definida: isso favoreceria tanto a permanência na Câmara quanto o êxito da carreira executiva, especialmente, neste último caso, se o deputado disputar a prefeitura da cidade que forma sua principal base eleitoral.

A Tabela 2 apresenta os resultados dos testes dessas hipóteses:

Tabela 2

Perfil eleitoral e opções de carreira dos deputados federais paulistas (1991-2011)

\begin{tabular}{|c|c|c|c|c|c|c|c|}
\hline & & \multicolumn{2}{|c|}{ Saída } & \multicolumn{2}{|c|}{$\begin{array}{l}\text { Reeleitos vs não } \\
\text { reeleitos }\end{array}$} & \multicolumn{2}{|l|}{ Executivo } \\
\hline & & Outros & Saída & Reeleitos & $\begin{array}{l}\text { Não } \\
\text { reeleitos }\end{array}$ & Outros & Executivo \\
\hline \multirow{7}{*}{ Votação } & Mais votados & 119 & 16 & 80 & 21 & 189 & 13 \\
\hline & & ,4 & $\cdot, 4$ & 4,4 & $-4,4$ &,- 9 & ,9 \\
\hline & Votação intermediária & 116 & 16 & 63 & 41 & - & - \\
\hline & & ,2 & $\cdot, 2$ & $\cdot, 3$ & ,3 & - & - \\
\hline & Menos votados & 116 & 19 & 46 & 55 & 191 & 9 \\
\hline & & $\cdot, 6$ & ,6 & $-4,1$ & 4,1 & ,9 & $\cdot, 9$ \\
\hline & TOTAL & 351 & 51 & 189 & 117 & 380 & 22 \\
\hline & & \multicolumn{2}{|c|}{$\begin{array}{c}\chi^{2}=0,358 \\
(0,836)\end{array}$} & \multicolumn{2}{|c|}{$\chi 2=24,327(0,000)$} & $\mathrm{TEF}=(0,512)$ & \\
\hline \multirow{7}{*}{ Concentração } & $\begin{array}{l}\text { Maior concentração de } \\
\text { votos }\end{array}$ & 123 & 11 & 61 & 45 & 192 & 9 \\
\hline & & 1,9 & $-1,9$ & $\cdot 1,1$ & 1,1 & ,9 &,- 9 \\
\hline & $\begin{array}{l}\text { Concentração intermediária } \\
\text { de votos }\end{array}$ & 116 & 17 & 60 & 42 & . & . \\
\hline & & 0 & , 0 & $\cdot, 7$ & ,7 & . & . \\
\hline & $\begin{array}{l}\text { Menor concentração de } \\
\text { votos }\end{array}$ & 112 & 23 & 68 & 30 & 188 & 13 \\
\hline & & $\cdot 1,9$ & 1,9 & 1,9 & $\cdot 1,9$ &,- 9 & ,9 \\
\hline & TOTAL & 351 & 51 & 189 & 117 & 380 & 22 \\
\hline & & \multicolumn{2}{|c|}{$\begin{array}{c}\chi^{2}=4,733 \\
(0,094)\end{array}$} & \multicolumn{2}{|c|}{$\chi 2=3,583(0,167)$} & $\mathrm{TEF}=(0,512)$ & \\
\hline \multirow{8}{*}{ Competitividade } & Maior competitividade local & 127 & 6 & 64 & 41 & 184 & 15 \\
\hline & & 3,5 & $-3,5$ & $\cdot, 2$ & ,2 & $-1,8$ & 1,8 \\
\hline & $\begin{array}{l}\text { Competitividade local } \\
\text { intermediária }\end{array}$ & 113 & 22 & 63 & 34 & - & . \\
\hline & & $\cdot 1,5$ & 1,5 & ,8 & $\cdot, 8$ & . & . \\
\hline & $\begin{array}{l}\text { Menor competitividade } \\
\text { local }\end{array}$ & 111 & 23 & 62 & 42 & 196 & 7 \\
\hline & & $\cdot 1,9$ & 1,9 & $\cdot, 6$ & ,6 & 1,8 & $\cdot 1,8$ \\
\hline & TOTAL & 351 & 51 & 189 & 117 & 380 & 22 \\
\hline & & \multicolumn{2}{|c|}{$\begin{array}{c}\chi^{2}=12,038 \\
(0,002)\end{array}$} & \multicolumn{2}{|c|}{$\chi 2=0,649(0,723)$} & $\mathrm{TEF}=(0,082)$ & \\
\hline
\end{tabular}

Fonte: Banco de dados sobre carreiras políticas dos deputados federais paulistas (1991-2011). 
MANCUSO, W. P. et al. Determinantes dos padrões de carreira política dos deputados...

Os dados da Tabela 2 confirmam a hipótese acerca do efeito da competitividade local sobre a opção de saída: de fato, os deputados localmente mais competitivos, na eleição anterior, optam mais pela permanência na vida política ${ }^{14}$. 0 efeito da concentração eleitoral sobre a opção de saída também se aproxima de valores estatisticamente significativos, mostrando que os deputados com votação mais concentrada, na eleição anterior, desistem menos da carreira política ${ }^{15}$. Em outras palavras, a Tabela 2 sugere que, entre os deputados federais paulistas, a decisão de abandonar a vida política pode estar ligada à dificuldade de constituir uma base eleitoral geograficamente definida. Não há evidências de efeito do indicador "grupos de votação" sobre essa opção de carreira, achado que diverge do encontrado por Leoni, Pereira e Rennó (2003) para o Brasil como um todo nas eleições de 1998.

No que diz respeito à opção estática, a Tabela 2 confirma a hipótese acerca do índice de votação. Isto é, os deputados mais votados na eleição anterior tendem a ser mais bem sucedidos na campanha de reeleição; e os menos votados tendem a ser menos bem sucedidos. Esses resultados, que convergem com os achados de Pereira e Rennó (2007) para as eleições de 1998 e 2002 e de Speck e Mancuso (2012) para as eleições de 2010, reafirmam a importância do acúmulo de capital político para a estabilidade das carreiras. Não há evidências significativas em apoio às demais hipóteses.

Quanto à opção executiva, o efeito da competitividade local aproxima-se de valores estatisticamente significativos, sugerindo, conforme esperado, que os candidatos capazes de construir uma base eleitoral geograficamente delimitada tendem a ser mais bem sucedidos nesta opção. É importante registrar que todos os cargos executivos disputados foram cargos de prefeitos municipais. Este é o caso, por exemplo, do deputado federal Celso Giglio, que apresentou alto índice de competitividade local nas eleições de 1998 e, em 2000, foi eleito prefeito da cidade de Osasco.

A segunda variável independente focalizada neste artigo é o pertencimento do deputado à base de apoio presidencial na Câmara. Os indicadores dessa variável são: i) a presença do partido do parlamentar na base de apoio ao Presidente no dia da eleição para deputado federal; e ii) o percentual de votos favoráveis, em plenário, às propostas legislativas do Poder Executivo, ao longo do mandato em vigor $^{16}$. No que se refere ao primeiro indicador, os deputados foram divididos em dois grupos: o grupo dos correligionários de partidos da base e o grupo dos demais. Quanto ao segundo indicador, os deputados foram separados em três grupos de tamanho aproximadamente igual: o grupo dos deputados que mais apoiaram as propostas do Executivo; o grupo de apoio intermediário e o grupo de menor apoio $^{17}$.

\footnotetext{
14 Para testar a hipótese de associação entre as variáveis nas tabelas de contingência, foram usados o teste exato de Fisher, nas tabelas $2 \times 2$, e o teste qui-quadrado de Pearson, nas tabelas $2 \times z>2$. $0 p$-value dos dois testes indica a chance de erro em afirmar que as variáveis estão associadas. 0 p-value usualmente aceito em trabalhos científicos para rejeitar a hipótese nula de desassociação entre as variáveis é igual ou menor a 0,05 (o que significa cinco por cento ou menos de chance de erro em apontar associação entre as variáveis). Esse valor foi usado como referência neste artigo. Quando o $p$-value dos testes foi significativo, procedeu-se à análise do resíduo ajustado, que se refere a cada célula da tabela, tomada individualmente. 0 resíduo ajustado indica que há mais casos do que o esperado numa célula quando é igual ou maior que $+2,0$ e que há menos casos que o esperado numa célula quando é menor ou igual a -2,0.

15 Há trabalhos que aceitam $p$-value igual ou menor que 0,1 para rejeitar a hipótese nula.

16 Os dois indicadores foram construídos a partir de informações do "Banco de Dados Legislativos" do Centro Brasileiro de Análise e Planejamento (CEBRAP). Este banco de dados foi gentilmente cedido pelos pesquisadores responsáveis, aos quais agradecemos.

17 Leoni, Pereira e Rennó (2003), Pereira e Rennó (2003) e Pereira e Rennó (2007) também utilizam outros indicadores de pertencimento à base, quais sejam, os de proposição e execução de emendas orçamentárias. Optamos por não usar esses indicadores, pois, no site do Senado, estavam disponíveis apenas os dados orçamentários referentes ao período $2000-2009$.
} 
OPINIÃO PÚBLICA, Campinas, vol. 19, n², novembro, 2013, p. 430-448

As hipóteses testadas são as seguintes: i) a opção de saída é mais frequente entre os deputados cujos partidos não participam da base de apoio ao governo e entre os deputados que menos apoiam as proposições do Executivo; e ii) os deputados cujos partidos pertencem à base de apoio presidencial, e que mais apoiam as proposições do Executivo, tendem a ser mais bem sucedidos nas opções estática e executiva. O pressuposto é que pertencer à base do governo e apoiar suas propostas favorecem a liberação pelo Executivo federal de um montante maior de recursos para as bases eleitorais do deputado, o que, por sua vez, pode traduzir-se em maior número de votos. Isso favorece a permanência do deputado na carreira política - seja na busca de reeleição para a Câmara, seja na disputa pela chefia do Executivo municipal.

Tabela 3

Pertencimento à base e opções de carreira dos deputados federais paulistas (1991-2011)

\begin{tabular}{|c|c|c|c|c|c|c|c|}
\hline & & \multicolumn{2}{|c|}{ Saída } & \multicolumn{2}{|c|}{$\begin{array}{c}\text { Reeleitos vs não } \\
\text { reeleitos }\end{array}$} & \multicolumn{2}{|c|}{ Executivo } \\
\hline & & Outros & Saída & Reeleitos & $\begin{array}{c}\text { Não } \\
\text { reeleitos } \\
\end{array}$ & Outros & Executivo \\
\hline \multirow{6}{*}{ Pertence à base? } & não & 137 & 24 & 79 & 38 & 152 & 9 \\
\hline & & $-1,1$ & 1,1 & 1,6 & $\cdot 1,6$ & $\cdot, 1$ &, 1 \\
\hline & $\operatorname{sim}$ & 214 & 27 & 110 & 79 & 228 & 13 \\
\hline & & 1,1 & $\cdot 1,1$ & $-1,6$ & 1,6 & ,1 & $\cdot, 1$ \\
\hline & TOTAL & 351 & 51 & 189 & 117 & 380 & 22 \\
\hline & & \multicolumn{2}{|c|}{$\mathrm{TEF}=(0,287)$} & \multicolumn{2}{|c|}{$\mathrm{TEF}=(0,116)$} & \multicolumn{2}{|c|}{$\mathrm{TEF}=(1,000)$} \\
\hline \multirow{8}{*}{ Apoio ao governo } & Maior apoio & 121 & 13 & 68 & 42 & 192 & 9 \\
\hline & & 1,3 & $\cdot 1,3$ & 0 & 0 & ,9 &,- 9 \\
\hline & $\begin{array}{l}\text { Apoio } \\
\text { intermediário }\end{array}$ & 119 & 15 & 53 & 48 & $\cdot$ & - \\
\hline & &, 6 &,- 6 & $-2,3$ & 2,3 & $\cdot$ & . \\
\hline & Menor apoio & 111 & 23 & 68 & 27 & 188 & 13 \\
\hline & & $-1,9$ & 1,9 & 2,4 & $.2,4$ & $\cdot, 9$ &, 9 \\
\hline & TOTAL & 351 & 51 & 189 & 117 & 380 & 22 \\
\hline & & \multicolumn{2}{|c|}{$x 2=3,773(0,152)$} & \multicolumn{2}{|c|}{$x 2=7,565(0,023)$} & \multicolumn{2}{|c|}{$\mathrm{TEF}=(0,512)$} \\
\hline
\end{tabular}

Fonte: Banco de dados sobre carreiras políticas dos deputados federais paulistas (1991-2011).

A Tabela 3 mostra que não há evidências favoráveis às hipóteses referentes às opções de saída e executiva. Em primeiro lugar, isto significa que, ao contrário do esperado, o abandono da carreira política não é mais frequente entre os deputados federais paulistas que se opõem ao governo de plantão. Dito de outra forma, a sobrevivência política dos deputados paulistas parece não depender exclusivamente da proximidade com o Executivo federal e da maior facilidade, daí decorrente, de direcionar recursos para as bases eleitorais.

Em segundo lugar, significa que, no estado de São Paulo, o pertencimento à base não afeta o êxito dos deputados federais que resolvem disputar, na metade de seus mandatos, o cargo de prefeito. Bourdoukan (2005, p. 75) sugere que a ambição executiva é mais frequente entre deputados oposicionistas, por causa da dificuldade de acesso deste subgrupo a recursos públicos. Os dados disponíveis para o estado de São Paulo, no período estudado, não sustentam claramente a tese de Bourdoukan, mas mostram que os oposicionistas que decidem candidatar-se a prefeito não enfrentam um handicap significativo. 
MANCUSO, W. P. et al. Determinantes dos padrões de carreira política dos deputados...

Por outro lado, o nível de apoio ao governo parece ser um fator relevante para aqueles que escolheram a opção estática, mas, de forma surpreendentemente diversa do que o suposto pela hipótese deste artigo e dos resultados obtidos por Pereira e Rennó (2007) e Botero e Rennó (2007) para as eleições de 1998 e 2002 no Brasil como um todo. De fato, a Tabela 3 mostra que há mais casos de candidatos bem sucedidos do que o esperado no subgrupo de menor apoio, e menos casos de candidatos bem-sucedidos do que o esperado no subgrupo de apoio intermediário. No subgrupo de maior apoio, não se notam diferenças estatisticamente significativas. Estes achados contraintuitivos podem estar relacionados com o fato de que tanto o PSDB como o PT elegem, tradicionalmente, muitos deputados pelo estado de São Paulo. Em quatro dos cinco períodos focalizados neste artigo, os Presidentes da República foram eleitos por esses dois grandes partidos brasileiros, que têm se colocado, desde então, em campos políticos opostos (LIMONGI e CORTEZ, 2010). Nas legislaturas 50 e $51^{\mathrm{a}}$, por exemplo, embora Fernando Henrique Cardoso (PSDB) estivesse à frente da Presidência da República, o estado de São Paulo elegeu uma forte bancada petista para a Câmara dos Deputados, da qual, certamente, espera-se um índice relativamente baixo de apoio ao governo. Situação similar foi observada nas duas legislaturas seguintes ( $52^{a}$ e $53^{a}$ ), em que Luiz Inácio Lula da Silva (PT) chefiou o Executivo federal e também se deparou com uma bancada de oposição no Congresso, composta, inclusive, por vários deputados tucanos eleitos pelo estado de São Paulo. É preciso notar ainda que a primeira metade da 49a legislatura foi marcada por forte oposição generalizada ao então presidente Fernando Collor de Mello. A segunda metade dessa legislatura, já no governo de Itamar Franco, também foi marcada por oposição, exercida no caso pela bancada do PT. Em síntese, o estado de São Paulo tradicionalmente elege bancadas fortes para os dois principais partidos nacionais, que ora estão na situação, ora na oposição. É provável, portanto, que o significativo número de deputados de oposição que sempre é eleito por esse estado tenha diminuído a associação entre o apoio ao governo e o êxito na opção estática.

A terceira variável independente aqui analisada é a ligação do deputado com a chapa eleitoral vitoriosa na disputa à Presidência. De fato, em todas as eleições focalizadas neste artigo, os pleitos para a Câmara e para a Presidência foram concomitantes, e a dinâmica de uma disputa pode afetar a outra. O indicador dessa variável é a presença do parlamentar na lista de candidatos dos partidos que formaram a chapa vitoriosa na disputa presidencial. Esse indicador divide os parlamentares em dois grupos: os candidatos da chapa vitoriosa e os demais. A hipótese testada é que a presença do parlamentar entre os candidatos da chapa vitoriosa aumenta a chance de êxito na disputa pela reeleição ${ }^{18}$. Esta hipótese complementa a anterior em dois sentidos: em primeiro lugar, porque a hipótese anterior investiga vantagens teoricamente possuídas pelos candidatos situacionistas, por serem da base de apoio ao governo, ao passo que a hipótese atual focaliza também eventuais vantagens dos candidatos oposicionistas, quando suas chapas saem vitoriosas na eleição presidencial - algo que, no período estudado, ocorreu nas eleições de 2002, vencidas pela chapa de Luiz Inácio Lula da Silva e José Alencar Gomes da Silva. Em segundo lugar, porque nem sempre as coligações eleitorais para a Presidência acompanham as coalizões de governo existentes na Câmara. Ou seja: partidos que hoje estão na base do

\footnotetext{
180 impacto dessa variável sobre a opção executiva não é estudado porque as eleições municipais não são concomitantes às eleições presidenciais. Também não é investigado o impacto da variável sobre a opção de saída, porque a decisão de se afastar da vida política muitas vezes é tomada antes da formalização das chapas que disputarão a Presidência da República.
} 
OPINIÃO PÚBLICA, Campinas, vol. 19, n², novembro, 2013, p. 430-448

governo podem não apoiar o candidato do governo na próxima eleição presidencial, e partidos que hoje estão na oposição podem vir a apoiar o candidato do governo na eleição seguinte.

Todavia, os dados da Tabela 4 não apresentam evidências que suportem esta hipótese. Isso quer dizer que o êxito dos deputados paulistas em suas campanhas de reeleição não depende de integrar a chapa vitoriosa no pleito presidencial.

Tabela 4

Pertencimento à chapa vitoriosa na disputa à Presidência

e opções de carreira dos deputados federais paulistas (1991-2011)

\begin{tabular}{|c|c|c|c|}
\hline & & \multicolumn{2}{|c|}{ Reeleitos x não reeleitos } \\
\hline & & Reeleitos & Não reeleitos \\
\hline \multirow{6}{*}{$\begin{array}{l}\text { Pertence à coligação presidencial } \\
\text { vitoriosa? }\end{array}$} & não & 108 & 77 \\
\hline & & $-1,5$ & 1,5 \\
\hline & $\operatorname{sim}$ & 81 & 40 \\
\hline & & 1,5 & $\cdot 1,5$ \\
\hline & TOTAL & 189 & 117 \\
\hline & & \multicolumn{2}{|c|}{$\mathrm{TEF}=(0,149)$} \\
\hline
\end{tabular}

Fonte: Banco de dados sobre carreiras políticas dos deputados federais paulistas (1991-2011).

A quarta variável independente focalizada neste artigo é o perfil de atuação parlamentar. Seis indicadores são utilizados: i) aprovação de normas jurídicas; ii) presença nas votações em plenário; iii) pertença à lista de "Cabeças do Congresso Nacional" do DIAP; iv) ocupação de cargos de liderança na Câmara dos Deputados; v) liderança de comissões permanentes e vi) liderança de comissões parlamentares de inquérito. $O$ indicador "aprovação de normas jurídicas" dividiu os deputados em dois grupos: o grupo dos deputados autores de, pelo menos, uma proposição legislativa que tenha sido transformada em norma jurídica durante o mandato, e todos os demais. O segundo indicador foi elaborado a partir da proporção de ausências dos parlamentares nas votações de plenário realizadas durante o mandato. Este indicador, construído a partir de informações do Banco de Dados Legislativos do CEBRAP, originou três grupos de parlamentares: o grupo dos deputados mais presentes, o grupo de presença intermediária, e o grupo dos mais ausentes. 0 terceiro indicador dividiu os parlamentares em dois grupos: os deputados identificados como "cabeças do Congresso Nacional" pela publicação anual de mesmo título do DIAP e os demais. O quarto indicador diferenciou dos demais todos os deputados que ocuparam pelo menos um dos seguintes cargos de liderança na Câmara durante o mandato: líder do governo, líder da bancada de partido, membro da Mesa Diretora, líder da maioria, líder da minoria ou líder de bloco parlamentar. Finalmente, os outros indicadores distinguiram dos demais os parlamentares que lideraram comissões permanentes ou CPIs durante seu mandato.

A hipótese que orienta a análise é que os seis indicadores desfavorecem a opção de saída e favorecem o êxito nas opções estática e executiva. Espera-se que os deputados federais que se destacam no exercício da função parlamentar tenham mais chances de permanecer na carreira política, seja no Legislativo ou no Executivo, por causa da projeção que obtêm. 
MANCUSO, W. P. et al. Determinantes dos padrões de carreira política dos deputados...

Tabela 5

Perfil de atuação parlamentar e opções de carreira dos deputados federais paulistas (1991-2011)

\begin{tabular}{|c|c|c|c|c|c|c|c|}
\hline & & \multicolumn{2}{|c|}{ Saída } & \multicolumn{2}{|c|}{$\begin{array}{l}\text { Reeleitos vs não } \\
\text { reeleitos }\end{array}$} & \multicolumn{2}{|c|}{ Executivo } \\
\hline & & Outros & Saída & Reeleitos & $\begin{array}{c}\text { Não } \\
\text { reeleitos }\end{array}$ & Outros & Executivo \\
\hline \multirow{5}{*}{ Aprovou normas jurídicas? } & Não & 313 & 48 & 170 & 103 & 341 & 20 \\
\hline & & $\cdot 1,1$ & 1,1 &, 5 & $\cdot, 5$ & $\cdot, 2$ & ,2 \\
\hline & Sim & 38 & 3 & 19 & 14 & 39 & 2 \\
\hline & & 1,1 & $-1,1$ & $\cdot, 5$ &, 5 & 0,2 & $.0,2$ \\
\hline & TOTAL & 351 & 51 & 189 & 117 & 380 & 22 \\
\hline & & \multicolumn{2}{|c|}{$\mathrm{TEF}=(0,455)$} & \multicolumn{2}{|c|}{$\mathrm{TEF}=(0,705)$} & \multicolumn{2}{|c|}{$\mathrm{TEF}=(1,000)$} \\
\hline \multirow{7}{*}{ Presença nas votações } & Mais presentes & 122 & 11 & 66 & 42 & 191 & 12 \\
\hline & & 1,9 & $\cdot 1,9$ & $\cdot, 2$ & ,2 & $\cdot, 4$ &, 4 \\
\hline & $\begin{array}{l}\text { Presença } \\
\text { intermediária }\end{array}$ & 117 & 20 & 59 & 42 & - & - \\
\hline & &,- 8 & 8 & $\cdot, 8$ & ,8 & & . \\
\hline & Menos presentes & 112 & 20 & 64 & 33 & 189 & 10 \\
\hline & & -1 & 1 & 1 & $\cdot 1$ & ,4 & $\cdot, 4$ \\
\hline & TOTAL & 351 & 51 & 189 & 117 & 380 & 22 \\
\hline & & \multicolumn{2}{|c|}{$\chi 2=3,518(0,172)$} & \multicolumn{2}{|c|}{$\chi 2=1,229(0,541)$} & \multicolumn{2}{|c|}{$\mathrm{TEF}=(0,827)$} \\
\hline \multirow{5}{*}{ Pertence à lista DIAP? } & não & 263 & 45 & 124 & 103 & 289 & 19 \\
\hline & & $-2,1$ & 2,1 & $-4,4$ & 4,4 & $\cdot 1,1$ & 1,1 \\
\hline & $\operatorname{sim}$ & 88 & 6 & 65 & 14 & 91 & 3 \\
\hline & & 2,1 & $\cdot 2,1$ & 4,4 & $.4,4$ & 1,1 & $\cdot 1,1$ \\
\hline & TOTAL & 351 & 51 & 189 & 117 & 380 & 22 \\
\hline & & \multicolumn{2}{|c|}{$\mathrm{TEF}=(0,035)$} & \multicolumn{2}{|c|}{$\mathrm{TEF}=(0,000)$} & \multicolumn{2}{|c|}{$\mathrm{TEF}=(0,436)$} \\
\hline \multirow{5}{*}{$\begin{array}{c}\text { Ocupou cargo de liderança } \\
\text { na Câmara? }\end{array}$} & não & 305 & 49 & 158 & 109 & 336 & 18 \\
\hline & & $-1,9$ & 1,9 & $-2,4$ & 2,4 &, 9 & $\cdot, 9$ \\
\hline & $\operatorname{sim}$ & 46 & 2 & 31 & 8 & 44 & 4 \\
\hline & & 1,9 & $-1,9$ & 2,4 & $-2,4$ & $\cdot, 9$ &, 9 \\
\hline & TOTAL & 351 & 51 & 189 & 117 & 380 & 22 \\
\hline & & \multicolumn{2}{|c|}{$\mathrm{TEF}=(0,064)$} & \multicolumn{2}{|c|}{$\mathrm{TEF}=(0,014)$} & \multicolumn{2}{|c|}{$\mathrm{TEF}=(0,317)$} \\
\hline \multirow{6}{*}{$\begin{array}{l}\text { Liderou comissão } \\
\text { permanente? }\end{array}$} & não & 234 & 35 & 120 & 80 & 252 & 17 \\
\hline & & $.0,3$ & 0,3 & $\cdot, 9$ & ,9 & $\cdot 1,1$ & 1,1 \\
\hline & $\operatorname{sim}$ & 117 & 16 & 69 & 37 & 128 & 5 \\
\hline & & 0,3 & $-0,3$ &, 9 & $\cdot, 9$ & 1,1 & $-1,1$ \\
\hline & TOTAL & 351 & 51 & 189 & 117 & 380 & 22 \\
\hline & & \multicolumn{2}{|c|}{$\mathrm{TEF}=(0,874)$} & \multicolumn{2}{|c|}{$\mathrm{TEF}=(0,391)$} & \multicolumn{2}{|c|}{$\mathrm{TEF}=(0,356)$} \\
\hline \multirow{6}{*}{ Liderou CPI? } & não & 325 & 49 & 171 & 110 & 352 & 22 \\
\hline & & $\cdot, 9$ & ,9 & $\cdot 1,1$ & 1,1 & $\cdot 1,3$ & 1,3 \\
\hline & $\operatorname{sim}$ & 26 & 2 & 18 & 7 & 28 & 0 \\
\hline & & ,9 &,- 9 & 1,1 & $\cdot 1,1$ & 1,3 & $\cdot 1,3$ \\
\hline & TOTAL & 351 & 51 & 189 & 117 & 380 & 22 \\
\hline & & \multicolumn{2}{|c|}{$\mathrm{TEF}=(0,556)$} & $\mathrm{TEF}=$ & 391) & $\mathrm{TEF}=($ & ,386) \\
\hline
\end{tabular}

Fonte: Banco de dados sobre carreiras políticas dos deputados federais paulistas (1991-2011).

A Tabela 5 oferece evidências de que o perfil de atuação parlamentar influencia as opções de carreira adotadas pelos deputados federais paulistas. A opção de saída é feita com menos frequência pelos "cabeças" do Congresso Nacional e pelos que ocupam cargos de liderança. O êxito na disputa pela reeleição está ligado aos mesmos indicadores, embora em sentido oposto. Isto é, tendem a ser significativamente mais bem sucedidos na opção estática os "cabeças" do Congresso e os ocupantes de cargos de liderança. É interessante notar que os indicadores associados à permanência na carreira política e ao êxito na reeleição são indicadores de posição (liderança) e de reputação (avaliação do DIAP), em vez de indicadores de produtividade (normas jurídicas aprovadas) ou assiduidade legislativa (presença nas votações). Esses dados corroboram o que Leoni, Pereira e Rennó (2003) apontaram em seu artigo: ao contrário do que afirma Samuels, os incumbents que se destacam no exercício da função 
OPINIÃO PÚBLICA, Campinas, vol. 19, n², novembro, 2013, p. 430-448

parlamentar não apenas tendem mais a disputar a reeleição, como levam vantagem nessa disputa. Um exemplo que ilustra a associação entre esses indicadores e a opção estática bem sucedida é o do deputado Eduardo Jorge, eleito pela primeira vez como deputado federal em 1990. Na 49a legislatura, o deputado integrou a lista do DIAP e liderou a bancada de seu partido - o PT, tendo sido reeleito nas duas legislaturas seguintes.

A Tabela 5 não mostra associação entre os seis indicadores e o êxito na eleição para prefeito, sugerindo, diferentemente de Leoni, Pereira e Rennó (2003), que, pelo menos no caso de São Paulo e para o período considerado, o bom desempenho da função parlamentar não favorece a ambição executiva.

A última variável independente focalizada neste artigo é o perfil de atuação partidária. Neste caso, utilizamos dois indicadores: i) ocupação de cargos de liderança partidária e ii) mudanças de partido. O primeiro indicador distingue dos demais os deputados que, durante o mandato, ocuparam também os cargos de presidente, vice-presidente ou secretário-geral de seus partidos políticos. O outro indicador diferencia dos demais os parlamentares que, ao longo do mandato, migraram de legenda pelo menos uma vez.

As hipóteses aqui são as seguintes: ocupar cargos de liderança partidária desfavorece a opção de saída e favorece as opções estática e executiva. Espera-se que a ocupação de cargos de liderança partidária incremente a visibilidade e a projeção política dos deputados, tanto perante o eleitorado como perante os correligionários e simpatizantes de seus partidos, favorecendo assim a permanência na vida política e o sucesso tanto na reeleição como na ambição executiva. Já a mudança de partido pode ter efeitos ambíguos, favorecendo ou desfavorecendo as opções de saída, estática e executiva, conforme dificulte ou facilite para o deputado migrante o encontro de legendas competitivas para futuras candidaturas.

Tabela 6

Perfil de atuação partidária e opções de carreira dos deputados federais paulistas (1991-2011)

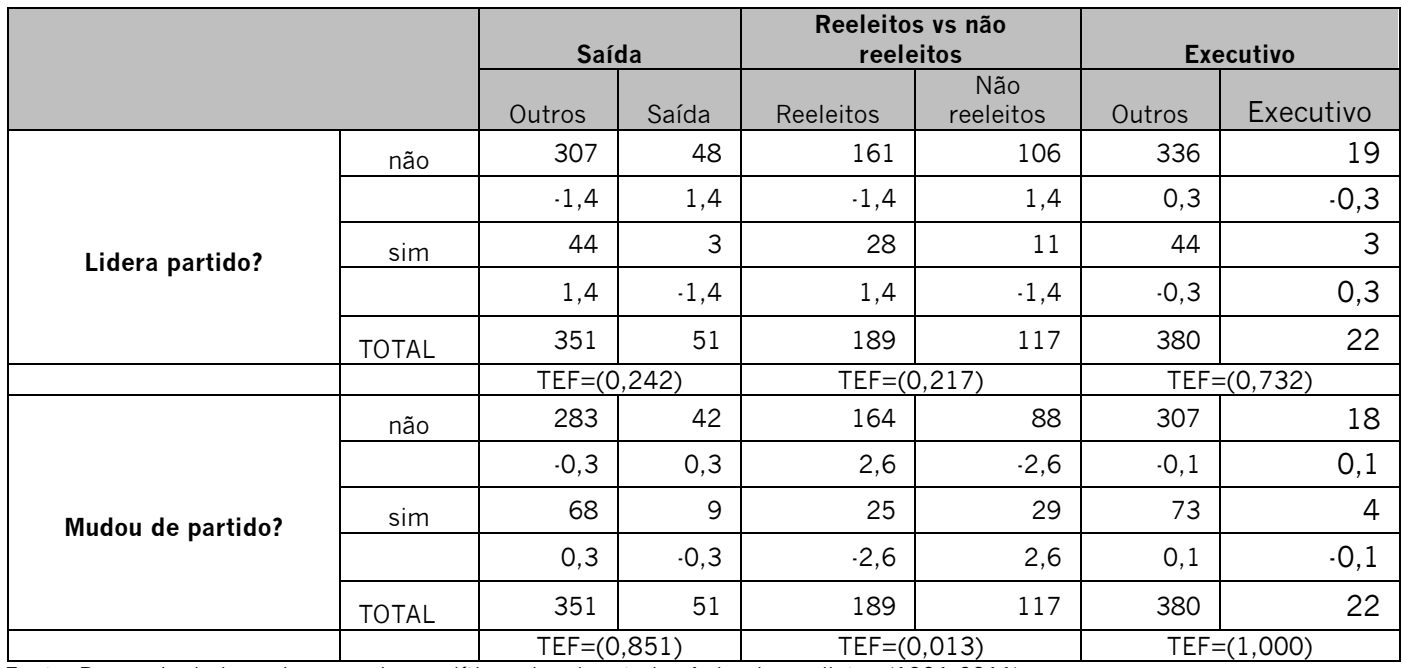

Fonte: Banco de dados sobre carreiras políticas dos deputados federais paulistas (1991-2011). 
MANCUSO, W. P. et al. Determinantes dos padrões de carreira política dos deputados...

A Tabela 6 não apresenta evidência de impacto da ocupação de cargos de liderança partidária sobre quaisquer opções de carreira. A migração partidária também não parece afetar a escolha da opção de saída ou o êxito em candidaturas ao Executivo. Porém, há evidências de que a migração partidária prejudica os deputados que se candidatam à reeleição, o que converge com os resultados de Pereira e Rennó (2007), mas contradiz a expectativa de ganhos eleitorais que, segundo Diniz (2000, p. 46), é o verdadeiro fator explicativo das mudanças de partido na Câmara dos Deputados. Portanto, tais evidências sugerem que o grau de identificação do candidato com seu partido importa e pode afetar sua carreira política. Este parece ter sido o caso, por exemplo, do deputado José Maria Eymael que, eleito para a 49a legislatura (1991-1995), mudou de partido duas vezes durante seu mandato. Na tentativa de reeleição para a $50^{a}$ legislatura, o deputado foi mal sucedido.

\section{Modelos de Regressão Logística}

As tabelas de contingência (Tabelas 2 a 6) apresentadas na seção anterior ajudam a identificar as variáveis associadas às diversas opções de carreira disponíveis aos deputados federais paulistas no período estudado. O objetivo desta seção é avançar mais um passo e encontrar o modelo de regressão logística mais bem ajustado a cada uma das opções de carreira. Nos três casos, o procedimento metodológico adotado é o mesmo. Em primeiro lugar, para cada opção de carreira, foram rodados modelos univariados de regressão logística para cada um dos indicadores apontados na seção anterior como estatisticamente significativos ou muito próximos disso (isto é, com o p-value do teste quiquadrado, ou do teste exato de Fisher, inferior, igual ou pouco superior a 0,05). Depois foram realizados testes para comparar a capacidade explicativa dos modelos univariados com a de modelos multivariados $^{19}$. Seguindo a recomendação de King, Keohane e Verba (1994, p. 182-185), acreditamos que é mais recomendável buscar o modelo de melhor ajuste incluindo nessa busca apenas as variáveis teoricamente relevantes e estatisticamente significativas do que: 1 . saturar os modelos com todas as variáveis disponíveis; 2. ver, a posteriori, o que "funcionou"; e 3. tentar encontrar uma explicação ex post para os resultados obtidos.

A primeira opção de carreira analisada nesta seção é a saída da vida política. Os testes mencionados mostram que o modelo mais ajustado para essa opção é o seguinte (Tabela 7):

\footnotetext{
19 O teste utilizado na comparação foi o seguinte: subtraímos do valor do teste da razão de verossimilhança dos modelos univariados [-2 Log Likelihood] o valor do mesmo teste para o modelo multivariado. A diferença obtida foi comparada com o valor apontado na tabela de qui-quadrado (com grau de liberdade igual ao número de variáveis acrescidas) como o valor necessário para uma chance de erro igual ou inferior a $5 \%$ em afirmar que o modelo multivariado é superior ao univariado. Quando o valor obtido pela subtração foi igual ou superior ao valor apontado na tabela do qui-quadrado, o modelo multivariado foi considerado de melhor ajuste aos dados. Tanto no caso dos modelos univariados, quanto no caso dos modelos multivariados, só foram aceitos os modelos que subsistiram simultaneamente a três testes - o de razão de verossimilhança, o de Hosmer-Lemeshow e o de Wald (Peng, Lee e Ingersoll, 2002). Quanto ao teste de razão de verossimilhança (que indica se o modelo testado é mais ajustado aos dados que o modelo "nulo", isto é, sem variáveis independentes), se o p-value foi menor que 0,05, então foi rejeitada a hipótese de que o modelo testado não é mais ajustado aos dados que o modelo nulo. Quanto ao teste de Hosmer-Lemeshow, se o p-value foi igual ou maior que 0,05, então, foi rejeitada a hipótese de que o modelo não se ajusta aos dados. Por fim, quanto ao teste qui-quadrado de Wald (que avalia a significância dos coeficientes de regressão), se o $p$-value foi menor que 0,05, então, foi rejeitada a hipótese de que os coeficientes de regressão não são significantes.
} 
OPINIÃO PÚBLICA, Campinas, vol. 19, n², novembro, 2013, p. 430-448

Tabela 7

Determinantes da opção de saída entre deputados federais paulistas (1991-2011)

\begin{tabular}{|c|c|c|c|c|c|c|c|c|c|c|c|c|c|}
\hline \multicolumn{4}{|c|}{ Avaliação do modelo } & \multicolumn{3}{|c|}{ Qualidade do ajuste } & & & & & & & \\
\hline \multicolumn{4}{|c|}{ Teste de razão de verossimilhança } & \multicolumn{3}{|c|}{ Hosmer-Lemeshow } & \multicolumn{7}{|c|}{ Modelo } \\
\hline$-2 \mathrm{LL}$ & $\chi^{2}$ & GL & $\mathbf{p}$ & $\chi^{2}$ & GL & $p$ & & $\beta$ & EP $\beta$ & Wald & GL & p & $\begin{array}{c}\text { Razão de } \\
\text { chances }\end{array}$ \\
\hline \multirow[t]{6}{*}{279,059} & \multirow[t]{6}{*}{26,770} & \multirow[t]{6}{*}{5} & \multirow[t]{6}{*}{000} & \multirow[t]{6}{*}{1,964} & \multirow[t]{6}{*}{8} & \multirow[t]{6}{*}{982} & Concentração alta & -,822 & , 400 & 4,217 & 1 & ,040 & ,439 \\
\hline & & & & & & & $\begin{array}{l}\text { Concentração } \\
\text { média }\end{array}$ & $\cdot, 380$ & ,357 & 1,133 & 1 & ,287 & ,684 \\
\hline & & & & & & & $\begin{array}{l}\text { Competitividade } \\
\text { alta }\end{array}$ & $\cdot 1,566$ & ,482 & 10,547 & 1 & 001 & ,209 \\
\hline & & & & & & & $\begin{array}{l}\text { Competitividade } \\
\text { média }\end{array}$ & ,055 & ,335 & ,027 & 1 & ,869 & 1,057 \\
\hline & & & & & & & Lista DIAP & $\cdot 1,204$ & , 460 & 6,862 & 1 & 009 & ,300 \\
\hline & & & & & & & Constante & $\cdot 1,021$ & ,295 & 11,970 & 1 & 001 & ,360 \\
\hline
\end{tabular}

Fonte: Banco de dados sobre carreiras políticas dos deputados federais paulistas (1991-2011).

A Tabela 7 aponta relação negativa e significativa entre a opção de saída e alto nível de concentração eleitoral, alto nível de competitividade local e pertencimento do deputado à lista de "cabeças" do Congresso Nacional, anualmente elaborada pelo DIAP. No que se refere à concentração eleitoral, o modelo mostra que a chance de saída dos candidatos com alto nível de concentração eleitoral corresponde a $43,9 \%$ da chance de saída dos candidatos com concentração eleitoral baixa, que foram tomados como grupo de referência. No que tange à competitividade local, o modelo indica que a chance de saída dos candidatos localmente mais competitivos corresponde a apenas 20,9\% da chance de saída dos candidatos menos competitivos, tomados como grupo de referência. Por outro lado, o modelo mostra que, em média, a chance de saída dos candidatos que pertencem à lista do DIAP de "cabeças" do Congresso Nacional corresponde a $30 \%$ da chance de saída dos demais candidatos. Em síntese, os achados deste artigo sugerem que a sobrevivência política dos deputados federais paulistas está ligada, sobretudo, à constituição de sólida base eleitoral local e à reputação de parlamentares com desempenho destacado. Ou seja, o deputado federal paulista que pretende continuar na política precisa cuidar do local, mas não pode descurar do nacional, mesmo que figure nas fileiras oposicionistas e não seja um exemplo de liderança ou fidelidade partidária. Assim, o presente artigo reforça e complementa os resultados de Florentino (2008), que mostra que o abandono da política está ligado a dois fatores: à dificuldade de obter destaque na atividade política (fator que atinge mulheres, novatos, suplentes e membros de partidos pequenos) ${ }^{20}$ e ao esgotamento da capacidade de participar e influir (fator que afeta os mais idosos, os envolvidos em escândalos e os ligados a partidos ou grupos em decadência).

A segunda opção de carreira focalizada é a opção estática. O modelo mais ajustado para essa opção é apresentado na Tabela 8:

\footnotetext{
${ }^{20}$ Segmentos menos presentes na lista de "cabeças do Congresso" do DIAP.
} 
MANCUSO, W. P. et al. Determinantes dos padrões de carreira política dos deputados...

Tabela 8

Determinantes do êxito na opção estática entre deputados federais paulistas

(1991-2011)

\begin{tabular}{|c|c|c|c|c|c|c|c|c|c|c|c|c|c|}
\hline \multirow{2}{*}{\multicolumn{4}{|c|}{$\begin{array}{c}\text { Avaliação do modelo } \\
\begin{array}{c}\text { Teste de razão de } \\
\text { verossimilhança }\end{array}\end{array}$}} & \multirow{2}{*}{\multicolumn{3}{|c|}{$\begin{array}{c}\begin{array}{c}\text { Qualidade do } \\
\text { ajuste }\end{array} \\
\text { Hosmer-Lemeshow }\end{array}$}} & \multirow{2}{*}{\multicolumn{7}{|c|}{ Modelo }} \\
\hline & & & & & & & & & & & & & \\
\hline$-2 \mathrm{LL}$ & $x^{2}$ & $\mathrm{GL}$ & $\mathrm{p}$ & $x^{2}$ & GL & $p$ & & $\beta$ & $\mathrm{EP} \boldsymbol{\beta}$ & Wald & GL & $p$ & $\begin{array}{l}\text { Razão de } \\
\text { chances }\end{array}$ \\
\hline \multirow[t]{5}{*}{356,867} & \multirow[t]{5}{*}{50,238} & \multirow[t]{5}{*}{4} & \multirow[t]{5}{*}{000} & \multirow[t]{5}{*}{3,191} & \multirow[t]{5}{*}{4} & \multirow[t]{5}{*}{,000 } & Votação alta & 1,638 & ,338 & 23,469 & 1 & ,000 & 5,146 \\
\hline & & & & & & & $\begin{array}{c}\text { Votação } \\
\text { média }\end{array}$ & ,729 & ,297 & 6,017 & 1 & ,014 & 2,072 \\
\hline & & & & & & & Lista DIAP & 1,263 & ,340 & 13,806 & 1 & ,000 & 3,535 \\
\hline & & & & & & & $\begin{array}{c}\text { Mudança de } \\
\text { partido }\end{array}$ & -,840 & ,329 & 6,504 & 1 & 011 & ,432 \\
\hline & & & & & & & Constante & -368 &, 226 & 2,644 & 1 &, 104 & ,692 \\
\hline
\end{tabular}

Fonte: Banco de dados sobre carreiras políticas dos deputados federais paulistas (1991-2011).

A Tabela 8 indica relação positiva e significativa entre, de um lado, o sucesso na reeleição e, de outro lado, o pertencimento à lista do DIAP e níveis mais altos de votação na eleição anterior. A Tabela 8 indica também relação negativa e significativa entre tal opção de carreira e a mudança de partido. Em outras palavras, os resultados do artigo sugerem que, no caso dos deputados federais paulistas, a permanência na Câmara é favorecida pelo capital político acumulado na carreira, tanto em termos eleitorais quanto em termos reputacionais, e é desfavorecida pela migração partidária. O modelo aponta que, em comparação com os candidatos menos votados na eleição anterior, tomados como grupo de referência, os candidatos mais votados têm chance 5,14 vezes maior de êxito reeleitoral, e os candidatos de votação intermediária têm chance 2,07 vezes maior. Já os candidatos que figuram na lista do DIAP têm chance de sucesso 3,53 vezes maior do que os candidatos que não aparecem nesta lista. Como dito anteriormente, este achado confirma a tese de Leoni, Pereira e Rennó (2003), segundo a qual o exercício destacado da função parlamentar serve não apenas como trampolim para realizar ambição "progressiva", mas também como meio de consolidar a carreira no Legislativo. Por fim, a chance de êxito reeleitoral dos candidatos que migram de partido corresponde, em média, a somente $43,2 \%$ da chance de sucesso dos candidatos que não migram. Este resultado corrobora a tese da importância dos partidos políticos brasileiros no momento eleitoral (BRAGA e PIMENTEL JR., 2011)21. O sistema eleitoral de representação proporcional com lista aberta, adotado nas eleições brasileiras para a Câmara dos Deputados (e também para as assembleias legislativas e para as câmaras de vereadores), muitas vezes, é criticado por enfraquecer os partidos políticos e o vínculo destes com os eleitores, levando a competição política a girar em torno de personalidades individuais e não de plataformas partidárias (MAINWARING, 1992-1993; AMES, 1995). Este artigo apresenta evidências em sentido contrário, ao indicar que os eleitores punem os deputados migrantes, prejudicando sua ambição estática22.

A última opção de carreira analisada pelo artigo é a opção executiva. O modelo mais ajustado para essa opção é o seguinte modelo univariado (Tabela 9):

${ }^{21}$ Sobre a grande importância dos partidos políticos brasileiros na arena parlamentar, ver Figueiredo e Limongi (2001).

22 A migração partidária no Brasil foi desestimulada pelas Resoluções do Tribunal Superior Eleitoral Nos. 22.610/07 e 22.733/08. Tais resoluções estabelecem que os partidos políticos podem solicitar à Justiça Eleitoral a decretação de perda de cargos eletivos de ex-correligionários, em caso de desfiliação partidária sem justa causa. Justas causas para desfiliação partidária seriam "a incorporação ou fusão do partido, a criação de novo partido, a mudança substancial ou o desvio reiterado do programa partidário e a grave discriminação pessoal”. Ver: <http://www.tse.jus.br/partidos/fidelidade-partidaria”> 
OPINIÃO PÚBLICA, Campinas, vol. 19, n², novembro, 2013, p. 430-448

Tabela 9

Determinantes do êxito na opção executiva entre deputados federais paulistas (1991-2011)

\begin{tabular}{|c|c|c|c|c|c|c|c|c|c|c|c|c|c|}
\hline \multirow{2}{*}{\multicolumn{4}{|c|}{$\begin{array}{c}\text { Avaliação do modelo } \\
\begin{array}{c}\text { Teste de razão de } \\
\text { verossimilhança }\end{array}\end{array}$}} & \multirow{2}{*}{\multicolumn{3}{|c|}{$\begin{array}{c}\text { Qualidade do ajuste } \\
\text { Hosmer-Lemeshow }\end{array}$}} & \multirow{2}{*}{\multicolumn{7}{|c|}{ Modelo }} \\
\hline & & & & & & & & & & & & & \\
\hline & $\chi^{2}$ & GL & $p$ & $\chi^{2}$ & GL & $p$ & & $\beta$ & $E P \beta$ & Wald & GL & $p$ & $\begin{array}{c}\text { Razão de } \\
\text { chances }\end{array}$ \\
\hline \multirow[t]{3}{*}{161,512} & \multirow[t]{3}{*}{9,100} & \multirow[t]{3}{*}{2} & \multirow[t]{3}{*}{.011} & \multirow[t]{3}{*}{, 000} & \multirow[t]{3}{*}{1} & \multirow[t]{3}{*}{1,000} & $\begin{array}{c}\text { Competitividade } \\
\text { alta }\end{array}$ & 1,341 &, 581 & 5,329 & 1 & ,021 & 3,824 \\
\hline & & & & & & & $\begin{array}{c}\text { Competitividade } \\
\text { média }\end{array}$ & $\cdot, 008$ & ,718 & ,000 & 1 & ,991 & ,992 \\
\hline & & & & & & & Constante & $\cdot 3,481$ &, 508 & 47,029 & 1 & ,000 & ,031 \\
\hline
\end{tabular}

Fonte: Banco de dados sobre carreiras políticas dos deputados federais paulistas (1991-2011).

A Tabela 9 evidencia relação positiva e significativa entre alto nível de competitividade local e êxito na ambição executiva, ou seja, a chance de um deputado eleger-se prefeito aumenta à medida que também aumenta sua competitividade local. Em média, a chance de sucesso dos deputados localmente mais competitivos é 3,8 vezes maior que a dos menos competitivos, tomados como grupo de referência. Ou seja, para os deputados com ambição executiva, a formação de bases eleitorais locais importa mais do que o pertencimento às fileiras governistas ou o destaque na atuação parlamentar. Este achado sugere que estratégias diversas favorecem deputados com ambições políticas diferentes: os que desejam permanecer na Câmara beneficiam-se ao acumularem capital político eleitoral e reputacional, bem como ao manterem a fidelidade partidária, enquanto os que desejam ser prefeitos precisam cultivar e fortalecer os laços locais ${ }^{23}$. Um bom exemplo para o modelo de opção executiva é o deputado federal Reinaldo Nogueira (PMDB), que, na eleição de 2006, obteve um altíssimo índice de competitividade local e, em 2008, foi bem sucedido na opção executiva para o cargo de prefeito da cidade de Indaiatuba.

\section{Considerações Finais}

Este artigo focalizou as opções de carreira política dos deputados federais paulistas no período das legislaturas 49a à 53a - isto é, entre 1991 e 2011. O esforço foi dirigido não apenas à investigação dos determinantes da opção estática, mas também da opção executiva e da opção de saída. A opção subnacional teve de ser desconsiderada por conta da limitação imposta pelo pequeno número de casos.

Inicialmente, investigamos o efeito de cinco variáveis sobre as três opções de carreira citadas anteriormente. Quanto ao perfil eleitoral, verificou-se que os deputados localmente mais competitivos e com votos mais concentrados, na eleição anterior, optaram menos pela saída. Já no que se refere à opção estática, constatou-se que o acúmulo de capital político eleitoral favorece a reeleição. Quanto à opção executiva, o efeito da competitividade local aproximou-se de valores estatisticamente significativos, sugerindo que os candidatos localmente mais competitivos tendem a ser mais bem sucedidos nessa opção de carreira.

O pertencimento à base não exerceu efeito significativo sobre as opções de saída e executiva. Entretanto, verificou-se associação entre essa variável e a opção estática, embora de forma distinta da

\footnotetext{
${ }^{23}$ Agradecemos ao parecerista anônimo por chamar a atenção para este ponto.
} 
MANCUSO, W. P. et al. Determinantes dos padrões de carreira política dos deputados...

expectativa inicial: no subgrupo de menor apoio, observam-se mais casos de candidatos bem sucedidos do que o esperado. Uma possível explicação para tal resultado reside no fato de que o estado de São Paulo costuma eleger bancadas fortes para PT e PSDB, que estão ora na situação, ora na oposição; o significativo número de deputados de oposição que sempre é eleito por esse estado pode ter diminuído a associação entre o apoio ao governo e o êxito na opção estática.

Os dados não apresentaram evidências em favor da hipótese de que o pertencimento do parlamentar à chapa eleitoral vitoriosa na disputa à Presidência aumenta a chance de êxito na disputa pela reeleição.

Quanto ao perfil de atuação parlamentar, os dados mostraram que os "cabeças" do Congresso Nacional e os deputados que se destacam no exercício do mandato optam menos pela saída e tendem a ser mais bem sucedidos na disputa pela reeleição.

Com relação ao perfil da atuação partidária, há evidências de que a mudança de partido desfavorece o êxito dos deputados que se candidatam à reeleição.

Em seguida, buscamos os modelos de regressão logística de melhor ajuste para cada opção de carreira. Sintetizando os achados, os modelos mostraram que, no estado de São Paulo, a opção de saída é mais frequente entre os deputados federais que não possuem uma base eleitoral geograficamente definida e que não têm atuação destacada no parlamento. Por sua vez, o sucesso na opção estática está ligado ao acúmulo de capital político eleitoral (votação expressiva em eleições anteriores) e reputacional (presença na lista do DIAP), bem como à fidelidade partidária. E o sucesso na opção executiva está ligado, sobretudo, à competitividade local.

As cinco legislaturas estudadas neste artigo foram analisadas em conjunto para que se pudesse obter uma visão geral sobre o padrão de carreiras políticas dos deputados paulistas no período focalizado. Em estudos futuros, o próximo passo é analisar as especificidades de cada legislatura. Outro passo interessante seria abarcar mais legislaturas e os deputados federais eleitos por outros - ou por todos - os estados brasileiros.

\section{Referências Bibliográficas}

AmES, B. “Electoral Strategy under Open-List Proportional Representation”. American Journal of Political Science, vol. 39, $n^{\circ} 2$, p. 406.433, May, 1995 .

BLACK, G. "A Theory of Political Ambition: Career Choices and the Role of Structural Incentives". American Political Science Review, vol. $66, n^{\circ} 1$, p. 144-159, Mar. 1972.

Botero, F.; Rennó, L. "Career choice and legislative reelection: evidence from Brazil and Colombia". Brazilian Political Science Review, São Paulo, vol. 1, n 1, p. 102-124, 2007.

Bourdoukan. "Ambição e carreiras políticas no Brasil". São Paulo. Dissertação de Mestrado em Ciência Política. Universidade de São Paulo, 2005.

Brace, P. "Progressive Ambition in the House: A Probabilistic Approach". Journal of Politics, vol. 46, n 2, p. 556.571, May, 1984.

Braga, M. do S. S.; Pimentel JR., J. "Os partidos políticos brasileiros realmente não importam?" Opinião Pública, Campinas, vol. $17, n^{\circ} 2$, p. $271 \cdot 303$, nov. 2011.

DıNız, S. “As migrações partidárias e o calendário eleitoral”. Revista de Sociologia e Política, Curitiba, n 15, p. 31-48, nov. 2000. 


\section{OPINIÃO PÚBLICA, Campinas, vol. 19, n², novembro, 2013, p. 430-448}

FIGUEIREDO, A.; LIMONGI, F. Executivo e Legislativo na nova ordem constitucional. 2a . edição. São Paulo: Editora FGV; FAPESP, 2001. Política orçamentária no presidencialismo de coalizão. São Paulo: Konrad Adenauer Stiftung; Editora FGV, 2008.

Florentino, R. "Saindo de cena: parlamentares que desistem da disputa eleitoral (1990-2006)". Revista de Sociologia e Política, Curitiba, vol. $16, n^{\circ} 30$, p. 45.63, jun. 2008.

KIEWIEt, R.; Zeng, L. "An analysis of Congressional career decisions, 1947-1986”. American Political Science Review, vol. 87, n² 4, p. 928-941, Dec. 1993.

KInG, G.; KeOHAne, R.; Verba, S. Designing Social Inquiry. New Jersey: Princeton University Press, 1994.

Leoni, E.; Pereira, C.; Rennó, L. "Estratégias para sobreviver politicamente: escolhas de carreiras na Câmara dos Deputados do Brasil”. Opinião Pública, Campinas, vol. 9, n 1, p. 44-67, maio 2003.

LIMONGI, F.; CoRTeZ, R. "As eleições de 2010 e o quadro partidário". Novos Estudos CEBRAP, n 88, p. 21.37, nov. 2010.

MaINWARING, S. "Brazilian Party Underdevelopment in Comparative Perspective". Political Science Quarterly, vol. 107, $\mathrm{n}^{\circ} 4$, p. 677-707, Winter 1992-1993.

PENG, C.Y; LeE, K.; INGERSOLL, G. "An introduction to logistic regression analysis and reporting". The Journal of Educational Research, vol. $96, n^{\circ} 1$, p. 1-14, Sept. 2002.

Pereira, C.; Rennó, L. "Successful re-election strategies in Brazil: the electoral impact of distinct institutional incentives". Electoral Studies, vol. 22, n 3, p. 425.448, set. 2003.

"O que é que o reeleito tem? O retorno: o esboço de uma teoria da reeleição no Brasil". Revista de Economia Política, São Paulo, vol. 27, n 4, p. 664-683, out.-dez. 2007.

ROHDE, D. "Propensão ao risco e ambição progressiva: o caso dos deputados federais nos Estados Unidos". Revista Brasileira de Ciência Política, Brasília, n 8, p. 209-236, maio-ago. 2012.

SCHLESInger, J. Ambition and Politics. Chicago: Rand McNally \& Company, 1966.

SPECK, B.; MANCUSO, W. "Financiamento, capital político e gênero: um estudo de determinantes do desempenho eleitoral nas eleições legislativas brasileiras de 2010". Trabalho apresentado no GT n 13 - "Financiamento político no Brasil", no XXXVI Encontro Anual da ANPOCS, Águas de Lindoia/SP, out. 2012.

Wagner Pralon Mancuso-pralon@usp.br

Carolina Uehara · carolinauehara@gmail.com

Anita de Cássia Sbegue - sbegue7@hotmail.com

Caroline Miranda Sampaio.ka.sampaio@gmail.com

Submetido à publicação em junho de 2012.

Versão final aprovada em outubro de 2013. 